\title{
Effects of Multimedia Redundancy in History Learning among 'Deep and Surface' Students
}

\author{
Sii Ching Hii \\ School of Educational Studies, University Science Malaysia \\ 11800 Gelugor, Penang, Malaysia \\ Tel: 60-1-6415-1224 E-mail: hii_sc@yahoo.com \\ Soon Fook Fong \\ School of Educational Studies, University Science Malaysia \\ 11800 Gelugor, Penang, Malaysia \\ Tel: 60-1-2525-4955 E-mail: ssfong@gmail.com
}

\begin{abstract}
The purpose of this study was to investigate the effects of redundant information in multimedia presentation in history learning. The two modes of multimedia presentation, namely multiple-channel presentation (text + graphics, pictures + redundancy audio, video and animation) and single-channel presentation (text + graphics + pictures) on history learning among deep and surface students were examined. The sample consisted of 240 Form One students from four Malaysian secondary schools. Findings of this study showed that students interacted with the MCP mode obtained significantly higher gain score compared to students interact with the SCP mode. Irrespective of the learning approaches, students using the MCP mode outperformed students using the SCP mode. Apparently, additional redundant information that are relevant to the contents within and across the visual and aural channels provide greater reinforcement in organizing and structuring information issuing in better learning. Results of this study suggest that cognitive load in multimedia-based learning can be minimized if adequate time is provided for comprehension and the pace of learning is under learner control.
\end{abstract}

Keywords: Redundant information, Multimedia presentation, Deep approaches, Surface students, History learning

\section{Introduction}

The discipline of history is intended to develop students' higher-order thinking skills in order to enable them to synthesize historical events so that they will have knowledge of foresight and hindsight. In the Malaysian schools, history is made a basic and compulsory subject by the Malaysian Ministry of Education. It has been regarded by the educators as an important subject for the younger learner to apprehend the nations, political, social, religious and economic problems; all of which can only be comprehended from the historical perspective.

While history is considered an important subject to study, it has been viewed by many students as an enumeration of facts, figures, dates, and otherwise "useless" and "dull" events (Weiner, 1995). Even so, students have a very negative attitude toward history and find history instruction irrelevant and meaningless where the emphasis was on rote memorization of accepted facts and conclusions in the textbooks (Yilmaz, 2009). There are also a large number of students who have no interest in history and see no reason for studying it, apart from its place in the examination system. This is because much of the history classroom is geared to the simple transmission of information through the use of single-textbook, the lecture method and teacher controlled question and answer strategies. The teaching of history has been reduced to a recitation of trivia with heavy emphasis on factual information which has little or no application to the daily lives of most students (Russell, 2008). In other words, the study of history is concerned mainly with the actions of peoples, not living enough to comprehend many of the experiences, which become a sort of generation gap built into the subject (Weiner, 1995).

While the field of history has been slow to recognize the potential of multimedia, findings from the field of cognitive psychology indicate that multimedia is likely to enhance learning to the extent that it is interactive, 
multisensory, and emphasizes the importance of making links among ideas (Winn \& Snyler, 1996). Past research has shown that multimedia-based learning increased learners' achievement, allow them to become energetic and self-directed thinkers, also the ability to accommodate individual learning styles. (Hillis, 2001; Kiili, 2006; Moreno \& Valdez, 2005; Smith \& Woody, 2000; Wang, 2010). The infusion of multimedia-based learning technology into education has created a major impact on the instructional content development and the methods of transferring appropriate knowledge to learners.

This bring us to the challenge of using multimedia presentation in history which can be an essential means of recreating the past - how to present historical information alive, the intangible tangible, the past present, and also how we can reveal to students the excitement and relevance of historical study (Bulter \& Clouse, 1994). Given the concern faced by students in learning history, this study intends to exploit the potential of multimedia-based learning to teach students with the hope that it will show promise of aiding history teachers in motivating students to develop thinking skill, and translating abstract ideas into more concrete examples in order for the students to acquire knowledge more effectively by their own preferred learning approaches.

\section{Multimedia Presentation in History}

Computer technology today offers the possibility of much more diverse and interesting forms of multimedia interfaces through the use of advanced display facilities. Desktop, hardware and software have become more powerful, flexible, and sophisticated in the types of presentations that they can author and deliver; there has been a proliferation of authoring packages programs that can deliver high-fidelity sound, realistic color images in stills, graphics, and full motion video (Alessi \& Trollip, 2001; Allen, 2003). In this context, historians have concluded that microcomputers can make significant contributions to the teaching and learning of history. They note that computers facilitate the development and presentations of census material, historical simulations, and supplement instructional resources (Thomas, 1998). Moreover, the use of multimedia in the history classroom has more potential and challenges than in most other disciplines (Wiley \& Ash, 2005). Studies by past research showed that using multimedia computer technology in learning history significantly improve students' learning performance (Hillis, 2008; Walsh, 2003; Wallace, Karpouzis, Stefanou, Maglogiannis, \& Kollias, 2004; Yang, 2009).

Likewise, as an effective communication tool, multimedia program provides the user to use all their senses to explore the presentation. Sight is used to see the colorful display or animation; sound is used to hear digitized music or auditory narrative; touch is used to activate the mouse or touch screen display. In other words, the multimedia can stimulate more than one sense at a time, and in doing so, may be more attention getting and attention holding. Color slides, sound, illustrations, and moving images are intrinsically interesting. Through this mix mode of presentation techniques, the multimedia can appeal to learners who prefer to receive information by reading, those who learn best through hearing, and those who prefer hands-on environments. It appears to support the concept of computer-driven interactivity with the learner's ability to determine and control the sequence and content selection (Moore, Burton \& Myers, 1996). The introduction of this technology seems to be relevant for learners with their personal characteristics.

On the other hand, historians scholar has found that only 7 percent of successful communication between teachers and students come from the spoken word, but 55 percent came from visual element (Easley, 1998). This is especially valuable for history learning since the nature of the subject and the type of materials used to convey ideas and information are very visual. In additions, the computer can play a vital role because it has the capacity to both motivate learners and focus their attention more effectively on the task on hand, which are best suited to their abilities, needs, and interest (Grimley, 2007).

Given the power of multimedia, it is extremely important that the educators who use it for teaching start from a solid, thorough understanding of the human learning process (Clark \& Mayer, 2008). The researcher suggests that cognitive theory requires design procedures that create learning environments in which learning strategies are not entirely predetermined, but which requires that the environments be highly adaptive to student actions. Recent technologies that permit the development of virtual environments offer the best possibility for realizing this kind of learning environment. Given this promise, this study asserts that the students' learning gain in history should be more successfully met when using a multiple-channel presentation to facilitate cognitive processes grounded on Mayer's (2001) Cognitive Theory of Multimedia Learning and Sweller's Cognitive Load Theory $(2003,2005)$ among students with different learning approaches.

Mayer's Cognitive Theory of Multimedia Learning (2001) ascertain that learners are much more likely to learn effectively if information is presented both verbally and visually simultaneously. On the other hand, the necessity of adapting instructional to the constraints of the learner's cognitive system has been the main concern 
of Cognitive Load Theory (CTL). In order to stimulate effective learning, efficient instructional designs should be able to reduce extraneous cognitive load and at the same time increase germane cognitive load (Sweller, 2003, 2005).

However, recent studies by Schnotz and Kiirschner (2007) proposed a new perspective on CLT by suggesting that reduction of cognitive load is not always helpful for learning; learning could be improved by an increase of germane load by integrating multiple sources of information in order to create an adequate alignment of learner expertise and learning task difficulty. Whereas germane cognitive load would occur when specific cognitive activities are performed in addition to the ordinary performance of a learning task and which aim at the further improvement of learning (Schnotz \& Kiirschner, 2007). Whether the instructional materials impose extraneous cognitive load or germane cognitive load is not only affected by instructional design but is mediated by the learners' learning activities, which in turn depend on the motivational aspects - personal goals and interests of the learner (Gerjets \& Scheiter, 2003).

Whereas recent studies by Seufert, Schiitze and Brunken (2009) indicating that multiple information could be comprehend by highly capacity learners who are more capable to retrieving, storing and processing all the information at the same time in their working memory. Whether the requirements of learning with multiple learning materials could enhance learning depend on learner's memory strategy skills and working memory capacity. For learning to occur, learners must actively engage in processes that impose a germane cognitive load which is facilitated by the instructional design (Van Gog, 2009). These findings support the addictive effect of multiple-channel presentations. It is assumed that the combinations of redundant channels of information will encourage learners to engage in active learning by mentally representing the materials in words and in pictures and by mentally making connections between the pictorial and verbal representations. Both visual and auditory stimuli impact learner attention and this will eventually result in increased learning and retention.

Thus, the central issue in this study is to find out whether the multiple-channel presentation provided by multimedia courseware facilitates the learning of history by the students. It would focus on the level of interactivity, hypermedia environment and the control capability for the individual student to go through the multimedia-based lessons which are best suited to his preference and ability. By incorporating the multimedia technology through its variety of tools which provide rich information with the possibilities for individualized instruction and the interactive component, history topics will come alive for students, offering new light to boring facts with photographs, video, film, primary source documents, maps and music, making learning an active process and thus enhancing and facilitating their learning in history.

\section{Research Hypothesis}

The following three hypotheses were designed and tested.

$\mathbf{H}_{1}$ In a multimedia environment, students using the multiple-channel presentation mode (MCP) will obtain significantly higher gain score than students using the single-channel presentation mode (SCP).

$\mathbf{H}_{2}$ Deep approach students will obtain significantly higher gain score than surface approach students when exposed to the two modes of presentation.

$\mathbf{H}_{3}$ There will be an interaction effect between the presentation modes and the learning approaches of the students on the gain score.

\section{Methodology}

\subsection{Participants}

The subjects for this study consisted of 240 Form One students from four Malaysian schools. They range in age from $13-14$ years old. For each school, two intact classes were chosen. The students involved had not been exposed to the topic entitled "The Emergence of Nationalism", this topic was part of the requirements of the Form Two History syllabus. The subjects were randomly assigned into any one of the two instructional modes. Two different levels of presentation were given to two different treatment groups. Group 1 would learn the lesson with the MCP mode, group 2 would learn the lesson with the SCP mode.

\subsection{Materials}

Two versions of the multimedia courseware were developed by the researcher using the authoring tool Adobe Authorware 7 version. The two versions were MCP and SCP. These two modes had the same content, which was the meaning of Nationalism, internal and external factors which influenced the emergence of Nationalism. MCP involves simultaneous mode of multimedia presentations include text, graphics and still images with redundant video, sound and animation (text + graphics + pictures + redundant video, audio and animation). It provides the 
concept of computer-driven interactivity with the learner's ability to determine and control the sequence and concept selection. Whereas the SCP to a page-turner mode of presentation that is mainly text-based, static graphic and pictures (text + static graphic + pictures), without any redundant channel of presentation. Both the multimedia presentation setting was designed with learner control.

In accordance with the previous research on cognitive load theory which assumed that instructional messages should be designed in ways that minimize the chances of overloading the learner's cognitive system (Sweller, 2003, 2005), the multimedia courseware in this study adopted the pacing principle of multimedia design which assume that learners learning gain would increase by breaking a lesson into manageable segments (Clark \& Mayer, 2008); the multimedia-based lesson in this study were designed by establishing and mapping the relationship between the various parts of the content, outlined the content and sequencing the lesson. Students only had to deal with one paragraph text and one picture in each screen with additional redundancy information (audio, video and animation) in hypertext capability. Students were allowed to control the pace of presentation by clicking the 'continue' button to move to successive segments. Moreover, students are able to navigate the flow of the information by choosing whether to access the information with additional cues in audio, video or animation by clicking on the hypertext, students can even skip the additional information by clicking on the 'Exit' button. In this way, students have the options to study the materials over their own preferred presentation mode and are able to process the first segment of the presentation before moving to the next segment without overloading their cognitive system. The interface design was standardize as much as possible to make it consistent.

\subsection{Design}

The study followed a $2 \times 2$ factorial quasi-experimental design. The factors of the design are two modes of presentation (multiple-channel presentation and single-channel presentation). The independent variables in this study were the modes of presentation. The moderate variables were the students' learning approaches, which included the deep approach and surface approach. The dependent variables for this study were the gain score of the students. Students' gain score referred to the posttest score minus the pretest score. This research attempts to examine the relationships among instructional method (two modes of presentation), type of outcome (cognitive), and learning approaches (deep and surface).

\subsection{Steps taken to minimize threats to internal and external validity}

The following steps were taken to minimize threats to internal and external validity of the research design;

(i) To minimize threat to internal validity due to maturation or history of the subjects, the experimental study was carried out for a brief period of two weeks.

(ii) To minimize the "test-wise" effect, the pretest questions were rearranged and the posttest given two weeks later so that the students might not remember the questions given in the pretest.

(iii) The four schools were chosen carefully to ensure similarity in terms of age, sex, scholastic aptitude, racial composition, achievement and socio-economic status of the pupils.

(iv) To minimize the Hawthorne effects, the students were assigned randomly to one of the treatment groups just before the event. After a student was assigned to the group, the student was not allowed to interact with students from the other group.

(v) To minimize the experimenter effect, the study was conducted by teacher assistants with detailed descriptions of procedures and explicit directions.

\subsection{Procedure}

Two instructors administered the treatment. Both of them received instructions from the researcher on the experimental procedures prior to data collection. Two weeks before the instructional treatment, all 240 students were given the Cattell "Culture fair" Intelligent Test (to determine the intelligent level of the students), the Learning Process Questionnaire (LPQ) (to determine the learning approaches-deep or surface) and pretest in their respective classes. Before the subjects arrived to participate in the computer-based learning, the researcher prepared the computer laboratory by installing one of the two lessons into each computer. Upon arrival at the computer laboratory, each student was randomly assigned to one of the two experimental conditions. The first fifteen minutes were used for keyboard skills. During this time, the students learned to move and click the mouse, and learned to proceed with the multimedia lessons. They were given 90 minutes to complete the lesson. Immediately after interacting with the treatments, students were given the posttest. 


\section{Result}

An analysis of the main effects and interaction effects were performed. Results of the analysis were then discussed with the corresponding hypotheses in this study. The probability level of 0.05 was used to test statistical significance. An ANOVA was carried out on the Cattell "culture fair" Intelligent test score to determine homogeneity of the two groups of student. There was no significant difference in ability; $\underline{\mathrm{F}}(1,238)=$ $2.834, \mathrm{p}=0.094, \underline{\mathrm{MSe}}=42.648$. Thus, it was found that the two treatment groups were homogenous in term of ability.

\subsection{Main Effects}

In the MCP, the deep approach students obtained higher gain scores (mean gain score $=4.47$ ) compared to the surface approaches students (mean gain score $=4.08$ ). In the SCP, students with deep approach learning obtained higher gain scores (mean gain score $=3.51$ ). Thus, it was found that the deep approaches students benefited more from both the presentation modes. Students with deep approach of learning obtained a higher mean gain score (4.03) in both the treatment compared to students with surface approach of learning (3.73). There were significant differences between students who exhibited different learning approaches obtained different gain score when exposed to the two modes of presentation (Table 1).

Students who received the MCP mode obtained significant higher gain score compared to students who received the SCP mode. The ANOVA analysis (Table 2) revealed significant differences in learning gain between the modes, $\underline{\mathrm{F}}(1,236)=35.206, \underline{\mathrm{p}}<0.05, \underline{\mathrm{MS}}_{\mathrm{e}}=35.206$.

\subsection{Interaction Effects}

No significant interaction effects of learning gain were found between the presentation mode and the learning approaches of the students as shown in Table $3, \underline{\mathrm{F}}(1,236)=0.154, \underline{\mathrm{p}}=0.695, \underline{\mathrm{MSe}}=1.220$. Although the interaction effects between presentation mode and learning approaches were not significant, this study found that more learning was facilitated when the multimedia presentation were presented in the MCP mode.

\section{Discussion}

\subsection{MCP Effects and Learning}

The results of this study were supportive of the positive value of the MCP effect. It was found that the redundancy information (video, audio and animation) in MCP did result in a better learning performance compared to the non-redundancy information in SCP. This result differs significantly from prior research on multimedia learning and cognitive load which implies that less material can result in better learning. This finding can be explained in three possible ways.

The first explanation could be derived from Mayer's (2001) Cognitive Theory of Multimedia learning indicating that visually presented information is processed in the visual working memory whereas aurally presented information is processed in auditory working memory. Leaning increased when learners make sense of the presented material by attending to the relevant information, mentally reorganizing it and integrating it with what they already know. The result of this study support the prediction that additional redundant information within and across the visual and aural channels provide greater reinforcement in organizing and structuring information.

Secondly, the MCP mode of treatment in this study provided the learners with the maximum amount of usable cues. These additional cues (audio, video and animation) in the MCP mode seemingly enhanced learning from the on-screen text and images. The provision of these cues helped learners achieve deeper understanding of the learning materials. Studies by Sanchez and Gracio (2008) support the assumption that providing aids as usable cues in computer-based learning environments help learners executing their learning processes and overcoming cognitive constraints. Furthermore, recent studies by Guan (2009) indicating that the presence of redundant information alone did not impair learning, the additional information presented in both audio and visual forms with on-screen text did not interfere with each other but was harmonized or even reinforced. These findings supported the assumption of this study that redundant information in the MCP mode corresponds with equally more learning, as long as the information presented is consistent and relevant to the subject area.

Finally, recent studies by Clark and Mayer (2008) explained the psychological reasons for exceptions to redundancy principle that presenting concurrent narration or animation, on-screen text and static graphics under learner control is less likely to cause cognitive overload in the visual channel because learner has time to process all of the incoming information. Students in this study especially in the MCP mode spent more than 90 minutes studying the instructional materials. When more time is available, students can reread text portions, listen to a piece of text as many times as they wishes or review animations without the danger of missing important 
information and at the same time they were able to comprehend and understand the instruction materials thoroughly. This finding is consistent with the studies by Tabbers, Martens and Van Merriennoer (2004) which stated that extraneous cognitive load cause by redundancy effect in short learning tasks may lose it influence as more time related factors become dominant in the learning process. Stiller, Freitag, Zinnbauer and Freitag (2009) indicating that learner pacing in multimedia instructions reduce mental effort and enhance learning. These researches supported the finding of this study that increased the level of interactivity and control capability for the student to go through the MCP modes of presentation by their own pace increased their learning gain. MCP instruction is more effective when the learner can set the pace; pictures, text, audio, video and animation can be perceived simultaneously, resulting in a decrease extraneous load.

Hence, students' learning gain was fostered from a history lesson when textual, pictures and graphics explanations were presented with redundant video, audio and animation than the same information presented from a single channel only without any redundant video, audio and animation. Instead of increasing cognitive load due to redundant information, presenting information with redundant information is able to improve information processing and hence facilitate better learning.

\subsection{MCP Effects for Deep versus Surface Approach Learners}

The result of this study found significant differences in learning gains between deep and surface approach learners in both the multiple-channel and single-channel mode of presentations. Overall, the deep approaches learners obtained a higher gain scores than the surface approach learners irrespective of the treatment groups. There were several possible explanations to this finding. Firstly, the MCP effect was stronger for deep approach learners but weaker for surface approach learners. This could be interpreted within the context of the motive and strategy approaches to learning by John Biggs (1987). A deep approach refers to those occasions when students start with the intention of understanding the meaning of the learning task. A student adopting the deep approach is intrinsically motivated and prefers to use strategies to maximize understanding. Whereas students using the surface approach is extrinsically motivated and is inclined to study mechanically rather than to study for understanding.

It was possible that in this study, deep approach learners with the intention of understanding the learning task would focus their attention on the content as a whole, try to see the connections between different parts and thinking about the structure as a whole. Deep approach learners will more likely adopt a higher germane load than learners who adopt a surface approach of learning (Marton \& Saljo, 1984). In doing so, MCP treatment facilitate their natural learning strategies of seeing, hearing and doing, through the variety of tools which provide rich information: written text, graphics, still images, sound, and video. Utilization of a variety of presentation formats enhance learning when learners actively engage in processes that impose a germane load, which is facilitated by the MCP. Thus, deep approaches learners merited and benefited more from both the treatments.

Secondly, given that cognitive resources in the working memory were limited, deep approach learners were more able to allocate sufficient cognitive resources to build referential connections than surface approach learners. MCP was suggested to optimize the information-processing rate of deep approach learners. However, it was found that students with neither surface approach nor deep approach of learning utilizing the MCP generally showed more sophisticated understanding of the topic than students using the SCP. Deep approaches learners who received the MCP treatment obtained higher gain score than deep approach learners who received the SCP treatment. Furthermore, the surface approach learners who received the MCP treatment outperformed the surface approach learners who received the SCP treatment. This indicated that MCP is more successful in assisting the students to learn effectively compared to SCP.

This result supported the prediction of this study that MCP were cause learners to expand and find more about into the subject area thus creating a lasting interest in history. It was possible that the MCP mode of treatment in this study fulfilled the concept of computer-driven interactivity and the control capability for the individual student to go through the courseware which was best suited to their learning approach and abilities. Therefore, multimedia-based learning (MCP) instruction had practical value in today's history classroom, students in both deep and surface approach in the MCP treatments benefited from its use.

\section{Conclusion}

This study aimed to investigate the effects of the two modes of multimedia presentation among students with different learning approaches. The result of this study showed the positive effects of MCP mode of presentation among deep and surface approaches learners. However, deep approach learners showed significantly higher achievement and motivational scores than surface approach learners. 
This indicated that MCP could be an effective way to facilitate history learning among the deep and surface approach learners. The use of MCP with appropriate audio-visual presented redundantly appears to be an effective way to guide students to focus on the important facts in history, the students are provided with a rich opportunity to work interactively with both visual and verbal representations of complicated historical facts and to see the relationships between the various parts. This mode of presentation with a repertoire of video, sound, animation and text was able to reenact the actual scenario of independence in the Malaysian history which would otherwise be quite difficult to capture using textbook. However, future research is required to investigate the effect of multimedia-based learning in catering the needs of learners of different psychological aptitudes and examine more precisely how learners process redundant and non-redundant information at the same time.

\section{References}

Alessi, S.M. \& Trollip, S.R. (2001). Computer-Based Instruction: Methods and Development (3 ${ }^{\text {rd }}$ edition). New York: Prentice hall.

Allen, M. (2003). Michael Allen's Guide to e-Learning. New Jersey, John Wiley \& Sons, Inc.

Biggs, J.B. (1987). Student Approaches to Learning and Studying. Hawthorn, Victoria: Australia Council for Educational Research.

Bulter, J.D. \& Clouse, R.W. (1994). Educational technology and The teaching of History: Promise, Practice, and Possibilities. (ERIC Document Reproduction Service No. ED 373 005).

Clark, R.C. \& Mayer, R.E. (2008). E-Learning and The Science of Instruction: Proven Guidelines for Consumers and Designers of Multimedia Learning ( $2^{\text {nd }}$ edition), Pfeiffer.

Gerjets, P. \& Scheiter, K. (2003). Goal configurations and processing strategies as moderators between instructional design and cognitive load: Evidence from hypertext-based instruction. Educational Psychologist, 38, 33-41.

Grimley, M. (2007). Learning from Multimedia Materials: The relative impact of individual differences. Educational Psychology, 27( 4), 465-485.

Guan, Y.H. (2009). A Study on the Learning Efficiency of Multimedia-Presented, Computer-based Science Information. Educational Technology \& Society, 12(1), 62-72.

Hillis, P. (2001). Can Multimedia Response To the Critics? A Report From The History Classroom, History and Computing, 13(3), 239-252.

Hillis, P. (2008). Authentic learning and multimedia in history education, Learning, Media and Technology, 33(2), 87-99.

Kiili, K. (2006). Towards a participatory multimedia learning model. Educational Information Technology, 11, 21-32.

Marton, F. \& Saljo, R. (1984). Approaches to Learning. In Marton, F.D., Hounsell, D. \& Entwistle (Eds.), The experience of learning (pp.39-58). Edinburgh: Scottish Academic Press.

Mayer, R. E. (Ed.). (2005). The Cambridge handbook of multimedia learning. New York: Cambridge University Press.

Mayer, R.E. (2001). Multimedia Learning, Cambridge University Press, United Kingdom.

Mayer, R.E. (2002). Cognitive Theory and the Design of Multimedia Instruction: An Example of the Two-Way Street Between Cognition and Instruction. New Directions For Teaching And Learning, 89, 55-71.

Moore, D.M., Burton, J.K., \& Myers, R.J. (1996). Multiple-Channel Communication: The Theoretical and research Foundations of Multimedia. In Jonassen, David H. (Eds.), Handbook of Research For Educational Communications and Technology, 851-875. New York: Macmillan Library Reference.

Moreno, R. \& Valdez, A. (2005). Cognitive Load and learning Effects of having Students Organize Pictures and Words in Multimedia Environments: The Role of Student Interactivity and Feedback. Educational Technology Research \& Development, 53(3), 35-45.

Renninger, A., Hidi, S., \& Krapp, A. (1992). The role of interest in learning and development. Mahwah, NJ: Erlbaum.

Russell III, W.B. \& Pellegrino, A. (2008). Constructing meaning from historical Content: A research Study. The History Teacher, 32(2), 3-15. 
Sanchez, E. \& Gracia-Rodicio, H. (2008). The use of modality in the design of verbal aids in computer-based learning environment. Interacting with Computers, 20, 545-561.

Schnotz, W. \& Kiirschner, C. (2007). A Reconsideration of Cognitive Load Theory. Educational Psychology Review, 19, 469-508.

Seufert, T., Schiitze, M., \& Brunken, R. (2009). Memory characteristics and modality in multimedia learning: An aptitude - treatment - interaction study. Learning and instruction, 19, 28-42.

Smith, S.M., \& Woody, P.C. (2000). Interactive Effect of Multimedia Instruction and Learning Styles. Teaching of Psychology, 27, 220-223.

Stiller, K.D., Freitag, A, Zinnbauer, P. and Freitag, C. (2009). How pacing of multimedia instructions can influence modality effects: A case of superiority of visual texts. Australasian Journal of Educational Technology, 25(2), 184-203.

Sweller, J. (2003). Evolution of human cognitive architecture. In B. Ross (Ed.), The psychology of learning and motivation (pp. 215-266). San Diego: Academic Press.

Sweller, J. (2005). The Redundancy Principle in Multimedia Learning. In R. Mayer (Ed.), The Cambridge handbook of multimedia learning (pp.159-168). New York: Cambridge University Press.

Sweller, J., van Merriënboer, J. J. G., \& Paas, F. G. W. C. (1998). Cognitive architecture and instructional design. Educational Psychology Review, 10(3), 251-296.

Tabbers, H.K., Martens, R. L. \& Van Merriennoer, J.J.G. (2004). Multimedia Instructions and Cognitive Load Theory: Effects of modality and cueing. British Journal of Educational Psychology, 74, 71-81.

Thomas, J.D. (1998). Reflections on Teaching Freshman History in a Mobile - Computing Environment. In Trinkle, Dennis A. (Eds.), Writing, Teaching, and Research History in the Electronic Age (pp. 89-100). New York: M.E. Sharpe.

Van Gog, T., Kester, L., Nievelstein, F., Giesbers, B., \& Paas, F. (2009). Uncovering cognitive processes: Different techniques that can contribute to cognitive load research and instruction. Computers in Human Behavior. [Online] Available: http://www.elsevier.com/locate/comphumbeh.

Wallace, M., Karpouzis, K., Stefanou, M., Maglogiannis, I. \& Kollias, S. (2004). Electronic Roads in Historical Documents: A Student Oriented Approach. Education \& Information Technologies, 9(3), 271-289.

Walsh, B. (2003). History and ICT, The Historical Association, 45-46.

Wang, T.J. (2010). Educational Benefits of Multimedia Skills Training. TechTrends, January/February, 54(1), 47-57.

Weiner, Robert G. (1995). History: Teaching and Methods. Retrieved from ERIC database. (ED387402).

Wiley, J \& Ash, I.K. (2005). Multimedia Learning of History. In R. Mayer (Ed.), The Cambridge handbook of multimedia learning (pp.375-392). New York: Cambridge University press.

Winn, W. \& Snyder, D. (1996). Cognitive Perspectives in Psychology. In Jonassen, D.H. (Eds.), Handbook of Research For Educational Communications and Technology (pp.112 -142). New York: Macmillan Library Reference.

Yang, S.C. (2009). A case study of technology-enhanced historical inquiry. Innovations in Education and Teaching International, 46(2), 237-248.

Yilmaz, K. (2009). A Vision of History teaching and learning: Thoughts on history Education in Secondary Schools. The High School Journal, 37-46. 
Table 1. Means and Standard Deviations of the Gain Score in relation to Students' Learning Approaches

\begin{tabular}{cccc}
\hline Presentation modes & Mean & Std. Deviation & Cases \\
\hline Multiple-Channel Presentation & 4.34 & 2.94 & 125 \\
Deep approach & $\mathbf{4 . 4 7}$ & 2.84 & 85 \\
Surface approach & 4.08 & 3.16 & 40 \\
\hline Single-Channel Presentation & 3.48 & 2.6 & 115 \\
Deep approach & $\mathbf{3 . 5 1}$ & 2.62 & 43 \\
Surface approach & 3.42 & 2.78 & 240 \\
\hline For entire Population & 3.93 & 2.84 & 157 \\
Deep approach & $\mathbf{4 . 0 3}$ & 2.77 & 83 \\
Surface approach & 3.73 & 2.97 & \\
\hline
\end{tabular}

Table 2. ANOVA Summaries for Gain Score (Posttest- Prettest), by modes and Students' Learning approaches

\begin{tabular}{cccccc}
\hline Source of Variation & Sum of Squares & DF & Mean Square & F & Sig. of F \\
\hline Main Effects & 49.393 & 3 & 16.464 & 2.073 & 0.104 \\
Mode & $\mathbf{3 5 . 2 0 6}$ & 1 & $\mathbf{3 5 . 2 0 6}$ & 4.433 & $\mathbf{0 . 0 3 6}^{*}$ \\
Learning Approach & 3.260 & 1 & 3.260 & 0.410 & 0.522 \\
2 way Interactions & 1.220 & 1 & 1.220 & 0.154 & 0.695 \\
Mode Learning Approach & 1.220 & 1 & $\mathbf{1 . 2 2 0}$ & $\mathbf{0 . 1 5 4}$ & $\mathbf{0 . 6 9 5}$ \\
Explained & 49.393 & 3 & 16.464 & 2.073 & 0.104 \\
Residual & 1874.403 & 236 & 7.942 & & \\
Total & 1923.796 & 239 & & & \\
\hline
\end{tabular}

240 cases were processed

$\mathrm{P}<0.05$ 